to adjust for confounding variables, an OR of 2 (95\% CI 1.4 to 2.7) was found in workers having contact with faeces of inhabitants. In another cross-sectional study in 198 nursing home workers, an OR of 0.9 (95\% CI 0.5 to 1.9) was found in multiple logistic regression compared to non-exposed controls after adjusting for other risk factors. In the cohort of HCWs and non-exposed controls, workers seronegative for $\mathrm{H}$ pylori at baseline were followed up for at least 10 years, resulting in 2254 person-years (py) in the HCW group and 1284 in nonexposed controls. In HCWs an incidence rate for $H$ pylori infection of $0.53 / 100$ py ( $95 \%$ CI 0.28 to 0.93$)$ was found, compared to $0.39 / 100$ py $(95 \%$ CI 0.13 to 0.91$)$ in non-exposed controls, resulting in a rate ratio of 1.36 (95\% CI 0.43 to 4.21$)$.

Conclusions These results show the difficulty in interpreting cross-sectional studies. Results of a cohort study show a slightly increased incidence of $H$ pylori infection in HCWs compared to non-exposed controls.

\section{IS THERE AN OCCUPATIONAL RISK FOR TRANSMISSION OF HELICOBACTER PYLORI IN HEALTHCARE WORKERS?}

Antoon De Schryver, ${ }^{1}$ Myriam Van Winckel, ${ }^{2}$ Wim Van Hooste, ${ }^{3}$ Gratia Wullepit, ${ }^{3}$ Kathleen Cornelis, ${ }^{3}$ Anne-Marie Charlier, ${ }^{3}$ Karin Colemonts ${ }^{3}{ }^{1}$ University of Antwerp, Antwerp, Belgium; ${ }^{2}$ Ghent University, Ghent, Belgium; ${ }^{3}$ IDEWE Occupational Health Services, Leuven, Belgium

10.1136/oemed-2011-100382.106

Objectives Helicobacter pylori was discovered in 1984, but up to now the way it is transmitted is not clear. Direct person-toperson transmission is thought to be most likely and could be relevant to occupational transmission, particularly in healthcare workers (HCWs).

Methods Using serology, we studied the occupational risk for $H$ pylori in HCWs in two cross-sectional studies and one cohort study (follow-up 10 years).

Results In a cross-sectional study, $587 \mathrm{HCWs}$ working in institutions for children with mental disabilities with a documented high prevalence of $H$ pylori infection were compared to non-exposed controls. Using multiple logistic regression 